Article

\title{
Solidification of Municipal Solid Waste Incineration Fly Ash through Co-Mechanical Treatment with Circulation Fluidized Bed Combustion Fly Ash
}

\author{
Zhengzhen Yao, Zhonghui Xu* ${ }^{\mathbb{D}}$, Qin Shuai, Xiaoyue Chen, Zao Jiang ${ }^{\circledR}, X_{i}$ Peng, Yu Li, Ran An, \\ Xin Jiang and Han Li \\ Key Laboratory of Solid Waste Treatment and Resource Recycle, Ministry of Education, Southwest University of \\ Science and Technology, Mianyang 621010, Sichuan, China; swustzhengzhenyao@163.com (Z.Y.); \\ qinshuai_t@163.com (Q.S.); XiaoyueChenV@163.com (X.C.); 18281612117@163.com (Z.J.); \\ pengxi2014@163.com (X.P.); ly1213424918@163.com (Y.L.); an15528535995@163.com (R.A.); \\ jiangxin7777@foxmail.com (X.J.); lihan1099599@163.com (H.L.) \\ * Correspondence: xuzhonghui@swust.edu.cn; Tel.: +86-187-8056-5871
}

Received: 15 November 2019; Accepted: 24 December 2019; Published: 30 December 2019

\begin{abstract}
This study aims to explore the solidification performance of municipal solid waste incineration fly ash (MSWIFA) through co-mechanical treatment with circulation fluidized bed combustion fly ash (CFBCFA). The mineral characterization, physical properties, and leaching resistance of the solidified bodies are investigated by X-ray diffraction spectroscopy (XRD), Fourier transform infrared spectroscopy (FT-IR), Thermogravimetry-differential thermal analysis (TG-DTA), compressive strength, porosity, and leaching test, respectively. C-S-H, ettringite (AFt), and Friedel's salt (FS) are the predominant hydrate products in the CFBCFA based solidified bodies, which are similar to the cement based solidified bodies. However, CFBCFA based solidified bodies exhibit higher compressive strength (36.7 MPa) than cement based solidified bodies (11.28 MPa), attributing to the three reasons: lower porosity and more compact internal structure of CFBCFA based solidified bodies; large amounts of $\mathrm{Ca}(\mathrm{OH})_{2}$ originating from MSWIFA are conducive to promoting the hydration reaction extent and compressive strength of the CFBCFA based solidified bodies; excessive $\mathrm{Ca}(\mathrm{OH})_{2}$ would cause compressive strength deterioration for the cement based solidified bodies. The heavy metals $(\mathrm{Zn}, \mathrm{Cu}, \mathrm{Cr}, \mathrm{Cd}$, and $\mathrm{Pb})$ concentrations in the extraction solution of the CFBCFA based solidified bodies are far below the requirements of Chinese National Standard GB 5085.3-2007. The solidification of MSWIFA through co-mechanical treatment could be an ideal substitute for cement solidification technology.
\end{abstract}

Keywords: MSWIFA; CFBCFA; solidification; co-mechanical treatment; heavy metals

\section{Introduction}

MSWIFA generates from waste incinerators, which is regarded as hazardous solid waste due to the enrichment of easily leachable heavy metals and, in some cases, potentially organic pollutants [1]. To safely handle and dispose of MSWIFA, various treatment have been proposed including recovery of valuable component, stabilization with wood pellet ash, and solidification with cement $[2,3]$. Currently, cement solidification technology is widely proposed and investigated to deal with MSWIFA owing to its technical feasibility $[4,5]$. Unfortunately, cement production has defects of significant equipment investment, high energy consumption, high operating cost, and environmental pollution [6]. Therefore, more suitable material should be considered to replace cement to solidify MSWIFA.

The fly ash coming from circulation fluidized bed combustion boilers could encapsulate the heavy metals effectively due to the pozzolonicity and self-gelling properties and has the potential to be 
cement substitute to solidify MSWIFA [7,8]. Nevertheless, CFBCFA based solidified bodies would confront the risk of destructive expansion and strength reduction, which is related to the low soluble anhydrite and poor pozzolonicity of other components [9]. Thus, special measures should be taken into account to enhance the reactivity of CFBCFA.

Mechanical activation has been frequently applied in the field of preparing alkali-activated slag cement, which could increase the hydration reactivity of the solid waste by changing the particle size and specific surface [10-13]. As for CFBCFA, the grinding process could accelerate the hydration reaction of the anhydrite and other silica-alumina components, which is crucial to diminish the expansion of the hardened blocks [14,15]. Meanwhile, large amounts of calcium hydroxide and calcium oxide in MSWIFA not only provide an alkaline environment for the hydration reaction but also could be helpful to increase the pozzolonicity of the CFBCFA during co-mechanical treatment [16]. Moreover, co-mechanical treatment might reduce the porosity and improve the leaching resistance of the solidified bodies. Perhaps it is a practical method to solidify MSWIFA through co-mechanical treatment with CFBCFA.

As described above, the present study is undertaken to explore the solidification performance of MSWIFA through co-mechanical treatment with CFBCFA, and cement solidification technology is chosen for comparison. The mineralogical characterization, porosity, compressive strength, and leaching resistance of the solidified bodies are given full consideration.

\section{Materials and Methods}

\subsection{Materials}

The MSWIFA was supplied by Tongxing Waste Incineration Power Plant (Beibei District, Chongqing, China, Figure 1). The source of CFBCFA was Neijiang Baima Circulating Fluidized Bed Demonstration Power Station Co., Ltd. (Sichuan, China, Figure 1). The MSWIFA was mixed with CFBCFA at the weight ratio of 7:3. Then, the mixture was ground $5 \mathrm{~h}$ by high-energy ball milling (QM-WX4, Nanjing university instrument factory, $40 \mathrm{~Hz}$ ). The Portland cement was produced by Zhonglian Cement Plant (Sichuan, China). The detailed chemical constituents of MSWIFA, CFBCFA, and Portland cement are present in Table 1. The particle size distributions (Figure 2) of the raw materials and ground mixture were measured by Beckman Coulter LS13320 laser diffraction analyzer. It was observed that the ground mixture showed a narrower particle size $(\mathrm{d} 50=6.107 \mu \mathrm{m})$, which was much smaller than the MSWIFA, CFBCFA, and cement.

Table 1. Chemical constituents of MSWIFA, CFBCFA, and Portland cement (wt \%).

\begin{tabular}{ccccccccccc}
\hline Component & $\mathrm{CaO}$ & $\mathrm{Cl}$ & $\mathrm{Na}_{2} \mathrm{O}$ & $\mathrm{SO}_{3}$ & $\mathrm{~K}_{2} \mathrm{O}$ & $\mathrm{SiO}_{2}$ & $\mathrm{Fe}_{2} \mathrm{O}_{3}$ & $\mathrm{Al}_{2} \mathrm{O}_{3}$ & $\mathbf{M g O}$ & Others \\
\hline MSWIFA & 48.22 & 19.70 & 9.87 & 7.02 & 5.16 & 3.24 & 1.44 & - & - & 5.17 \\
CFBCFA & 9.64 & - & 0.44 & 7.96 & - & 45.60 & 15.16 & 17.10 & 0.98 & 3.12 \\
$\begin{array}{l}\text { Portland } \\
\text { Cement }\end{array}$ & 49.82 & - & 0.59 & 2.78 & 1.28 & 29.89 & 4.04 & 8.15 & 2.20 & 1.25 \\
\hline
\end{tabular}

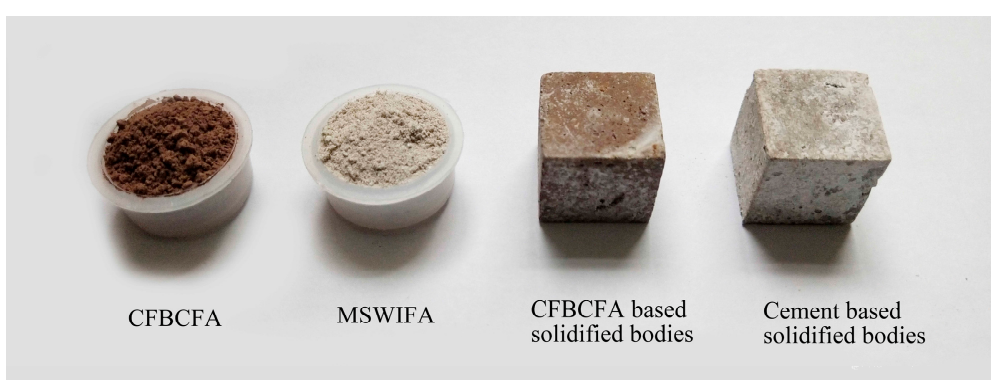

Figure 1. The appearance of MSWIFA, CFBCFA, CFBCFA and cement based solidified bodies. 


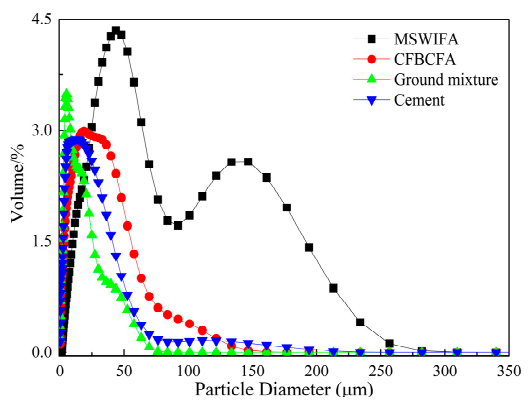

Figure 2. The particle size distributions of the raw materials and ground mixture.

\subsection{Sample Preparation}

The CFBCFA based solidified bodies were prepared with ground mixture and water at the mass ratio of 1:0.3 (Table 2). Cement based solidified bodies were also used to prepare an additional solidification matrix according to a fixed mass ratio (Cement:MSWIFA:water = 0.3:0.7:0.3). The mix designs of the solidified bodies were shown in Table 2. The slurries were cast into $20 \mathrm{~mm}$ cube molds and vibration for 10 min to remove entrained air bubbles. Subsequently, the molds were sealed by polyethylene plastic films and kept for $24 \mathrm{~h}$ at a standard curing condition $\left(20 \pm 1{ }^{\circ} \mathrm{C}, \geq 90 \%\right.$ relative humidity). After $24 \mathrm{~h}$, the samples were demolded and kept at the same conditions without the polyethylene film for a further 27 days. The prepared CFBCFA and cement based solidified bodies are shown in Figure 1.

Table 2. The mix designs of CFBCFA/Cement based solidified bodies ( $w \mathrm{t} \%$ ).

\begin{tabular}{ccccc}
\hline Material & Ground Mixture & Cement & MSWIFA & Water \\
\hline CFBCFA based solidified bodies & 100 & - & - & 30 \\
Cement based solidified bodies & - & 30 & 70 & 30 \\
\hline
\end{tabular}

\subsection{Analytical Methods}

\subsubsection{Mineralogical Characteristics}

The mineralogical characterization of the solidified bodies was characterized via X-ray diffraction spectroscopy (XRD), Fourier transform infrared spectroscopy (FT-IR), and Thermogravimetry-differential thermal analysis (TG-DTA). The XRD pattern was obtained with an X'Pert PRO (PANalytical B.V., Almelo, The Netherlands) multifunctional $X$-ray diffractometer using $\mathrm{CuK} \alpha$ radiation generated at $35 \mathrm{kV}$ and $40 \mathrm{~mA}$ and a scanning rate of $10^{\circ}$ per min from $3^{\circ}$ to $80^{\circ}(2 \theta)$. FT-IR spectrum in the $4000-400 \mathrm{~cm}^{-1}$ region was recorded by Nexus 670 infrared analyzer (PerkinElmer Scientific, Newark, New Jersey, USA) using the $\mathrm{KBr}$ pellet technique (0.5 mg powder sample mixed with $250 \mathrm{mg}$ of $\mathrm{KBr}$ ). The thermal behavior (TG-DTA) of the solidified bodies was tested by SDT Q160 synchronous thermal analyzer (TA Instruments, New Castle, DE, USA), which was heated from ambient to $1000^{\circ} \mathrm{C}$ in a nitrogen atmosphere.

\subsubsection{Porosity and Compressive Strength}

The porosity of solidified bodies was determined by Archimedes' principle [17] (Figure 3). Distilled water was used as the immersion medium during the procedure. After the curing period, the mass of the dried samples were determined $\left(\mathrm{m}_{\mathrm{dry}}\right)$; then, the samples were immersed into a Heat-gathering Style Magnetism Mixer (DF-101S) and boil for $5 \mathrm{~h}$; after the sample was cooled for $14 \mathrm{~h}$, the saturated mass of the samples after boiling was measured $\left(\mathrm{m}_{\mathrm{sat}}\right)$. From the knowledge of these masses, the effective porosity can be calculated following the standard of ASTM C642-2013. The compressive strength of solidified bodies was measured through a universal testing machine (CMT5504, Shanghai, China) according to the Chinese National Standard GB/T 17671-1999. The final 
results were obtained by calculating the average of six tests. Each test result was obtained by taking an average of the results from six specimens.

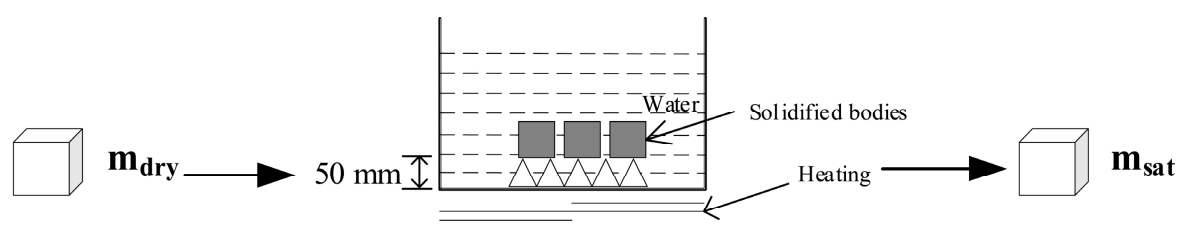

Measure the dry sample weight

Boil for 2 hours in a water bath

Measure the saturated sample weight

Figure 3. Schematic for measuring the porosity of CFBCFA and cement based solidified bodies.

\subsubsection{Leaching}

The heavy metal leaching from solidified bodies and MSWIFA was performed in accordance with the Chinese standard HJ/T 300-2007. Typically, the crushed samples collected after the compressive strength test should be dried in an oven with $105^{\circ} \mathrm{C}$ and ground in a ceramic mortar till the particle size was below $9.5 \mathrm{~mm}$. Subsequently, the powder and leaching agent with a liquid/solid ratio of 20 was put into a $2000 \mathrm{~mL}$ extraction bottle, which was fixed on a tumble-type oscillating device for $18 \mathrm{~h}$ at $30 \mathrm{rpm}$ (Figure 4). Finally, the extraction leachate was filtered through a vacuum filter and collected to measure the heavy metal contents by Atomic Absorption Spectroscopy (Analytik Jena, Jena, Germany).

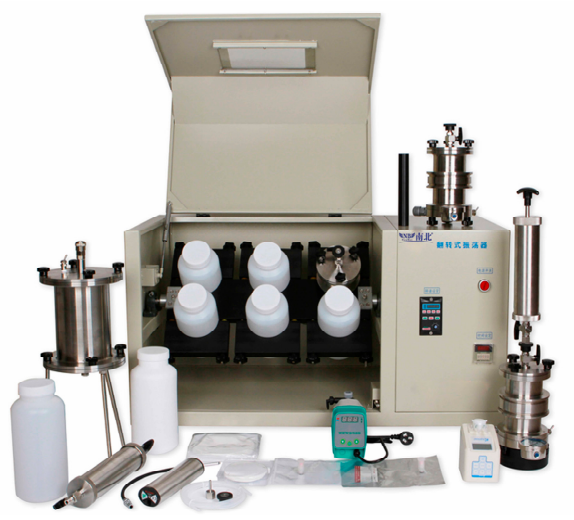

(a)

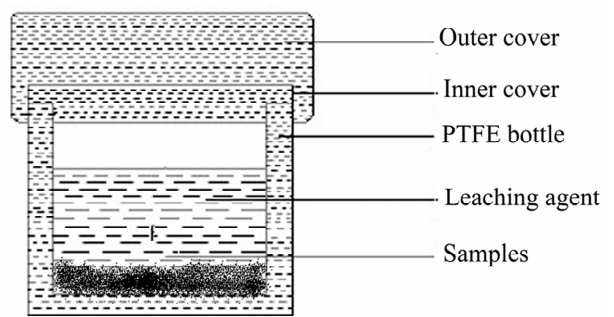

(b)

Figure 4. The device of leaching experimental, (a) Rotary Agitator; (b) extraction bottle.

\section{Results and Discussion}

\subsection{Mineral Characterization}

\subsubsection{X-Ray Diffraction Analysis}

The XRD patterns of the raw materials, ground mixture, and solidified bodies are shown in Figure 5. The main crystalline compounds in MSWIFA are calcium hydroxyl chloride, calcite, halite, anhydrite, and quartz, whereas the principal mineral phases of CFBCFA are anhydrite, hematite, and quartz. Compared to CFBCFA, the peak intensity of anhydrite in the ground mixture is obviously weakened, indicating the serious crystalline phase destruction during the co-mechanical treatment [15]. In addition, Friedel's salt (FS, $\left.\mathrm{Ca}_{3} \mathrm{Al}_{2} \mathrm{O}_{6} \cdot \mathrm{CaCl}_{2} \cdot 10 \mathrm{H}_{2} \mathrm{O}\right)$ is detected in the CFBCFA based solidified bodies, which is ascribed to the hydration reaction of $\mathrm{Al}_{2} \mathrm{O}_{3}$ with chloride and $\mathrm{Ca}(\mathrm{OH})_{2}[18,19]$. Meanwhile, ettringite (AFt) and gismondine are also found in the CFBCFA based solidified bodies, resulting from the hydration reaction between the $\mathrm{Ca}(\mathrm{OH})_{2}$ and the other active components in the ground mixture, which are helpful to hold the heavy metals in the crystalline structure with 
their ions exchange abilities [20,21]. Furthermore, C-S-H could be found in the CFBCFA and cement based solidified bodies, which is responsible for the strength development and heavy metals encapsulation [22]. In fact, FS, AFt and C-S-H are the predominant phases or hydration products in cement and CFBCFA based solidified bodies, implying that the similar hydration behavior occurs during the two solidification processes.

\subsubsection{Fourier Transform Infrared Analysis}

As can be observed in Figure 6, two broad bands around 3433 and $1631 \mathrm{~cm}^{-1}$ in all FT-IR spectrums are corresponded to the $\mathrm{O}-\mathrm{H}$ stretching vibration of hydration water and $\mathrm{H}-\mathrm{O}-\mathrm{H}$ bending vibration of interlayer water, respectively [23]. In Figure $6 \mathrm{~d}, \mathrm{e}$, the band around $3639 \mathrm{~cm}^{-1}(\mathrm{O}-\mathrm{H}$ bending vibration) is associated with the portlandite [24]. The band around $953 \mathrm{~cm}^{-1}$ is attributed to the $\mathrm{Si}-\mathrm{O}-\mathrm{Si}$ asymmetric stretching vibration, which could be correlated to $\mathrm{C}-\mathrm{S}-\mathrm{H}$ or gismondine $[25,26]$. The adsorption bands around $1123 \mathrm{~cm}^{-1}$ (S-O asymmetric vibration) together with $675 \mathrm{~cm}^{-1}$ (Al-OH bending vibration) represent the presence of $\mathrm{AFt}$ [5]. The $\mathrm{Al}-\mathrm{OH}$ bending vibration is detected around $788 \mathrm{~cm}^{-1}$ and always considered to be associated with FS [5,27]. The band around 875 and $1448 \mathrm{~cm}^{-1}$ are identified as the bending vibration and stretching vibration of $\mathrm{CO}_{3}{ }^{2-}$ [24]. FTIR analysis further demonstrates that $\mathrm{C}-\mathrm{S}-\mathrm{H}, \mathrm{AFt}$ and Fs are the dominant hydration products in cement and CFBCFA based solidified bodies, which is consistent with the XRD result.

\subsubsection{Thermogravimetry-Differential Thermal Analysis}

From the curves in Figure 7, there is a continuous weight decline of the both solidified bodies with about $25 \%$ of total weight loss over the whole testing temperature range. The endothermic peaks occurred before $200^{\circ} \mathrm{C}$ with around $13 \%$ weight loss are associated with the free water evaporation and the dehydration of C-S-H, AFt and FS [28-30]. The less pronounced shoulder around $286^{\circ} \mathrm{C}$ can be interpreted by the dehydration of small quantities of hydrocalumite [30,31]. At around 367 ${ }^{\circ} \mathrm{C}$ in Figure $4 \mathrm{a}$, a very small endothermic peak and weight loss correlated to the dehydration of portlandite are detected, yet the peak in Figure $4 \mathrm{~b}$ exhibits even stronger and shift to $400{ }^{\circ} \mathrm{C}$ since a relatively large amount of portlandite in cement based solidified bodies [32,33]. A large proportion of $\mathrm{Ca}(\mathrm{OH})_{2}$ originating from MSWIFA may not fully attend the main hydration reaction and is harmful to the compressive strength development of the cement based solidified bodies. The inconspicuous endothermic peak near $863^{\circ} \mathrm{C}$ accompanied by weight loss (approximately 7\%) in Figure 4a can be ascribed to the decomposition of $\mathrm{CaCO}_{3}$, while the peak appears at $667^{\circ} \mathrm{C}$ in Figure $4 \mathrm{~b}$ due to the more quantities of $\mathrm{CaCO}_{3}$ in cement based solidified bodies due to the large quantities of $\mathrm{Ca}(\mathrm{OH})_{2}$ in cement based solidified bodies [34]. The excessive $\mathrm{Ca}(\mathrm{OH})_{2}$ in cement based solidified bodies indicates that large amounts of calcium hydroxide and calcium oxide haven't joined in the dominant hydration reactions during the cement solidification process, which is harmful to the strength development of the solidified bodies. 


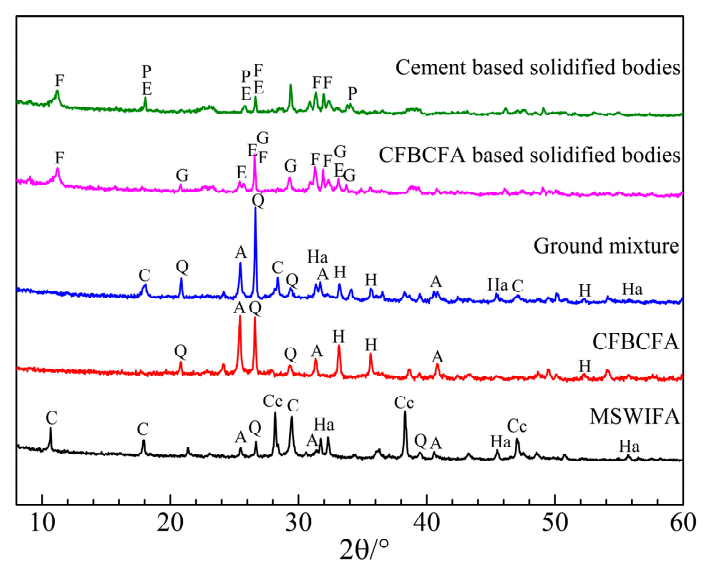

Figure 5. XRD patterns for the raw materials, ground mixture, and solidified bodies (A-Anhydrite; C-Calcite; E-Ettringite; F-Friedel's salt; G-Gismondine; H-Hematite; Ha-Halite; P-Portlandite; Q-Quartz; Cc-Calcium hydroxyl chloride).

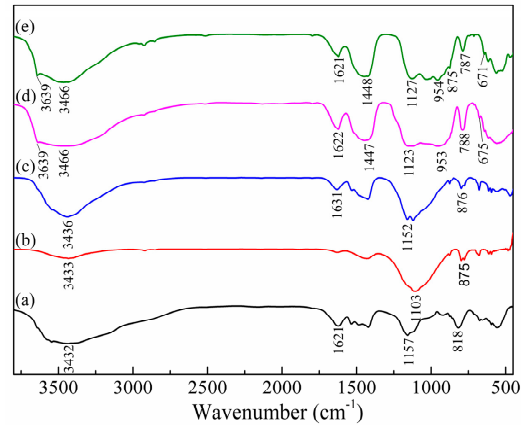

Figure 6. FT-IR spectrums for the raw materials (a-MSWIFA, b-CFBCFA), ground mixture (c), and solidified bodies (d-CFBCFA based solidified bodies, e-Cement based solidified bodies).
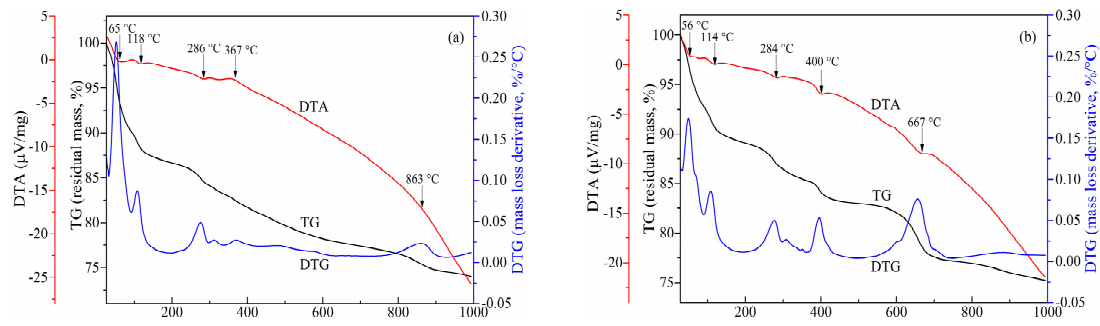

Figure 7. TG-DTA curves for solidified bodies (a)-CFBCFA based solidified bodies; (b)-cement based solidified bodies.

\subsection{Porosity and Compressive Strength}

The compressive strength of CFBCFA based solidified bodies (36.70 MPa) is much higher than that of cement based solidified bodies (11.28 MPa), which is correlated to the lower porosity (Table 3) and more compact internal structure of CFBCFA based solidified bodies. As shown in Table 3, the porosity of CFBCFA and cement based solidified bodies are $18 \%$ and $24.5 \%$, respectively, which could be related to the $\mathrm{w} / \mathrm{c}$ ratio and degree of hydration reaction for the matrices [35]. In practice, a significant decrease of the particle size of the ground mixture (Figure 2) is conducive to forming an even denser structure for CFBCFA based solidified bodies. Meanwhile, co-mechanical treatment increases the pozzolonicity and enhances the hydration reaction extent, which is beneficial to the strength development of CFBCFA based solidified bodies [36]. Moreover, huge amounts of $\mathrm{Ca}(\mathrm{OH})_{2}$ originating from the MSWIFA do not completely participate in the formation of $\mathrm{C}-\mathrm{S}-\mathrm{H}$ during the hydration process, which would cause compressive strength deterioration for the cement based solidified bodies. Compared with other studies [37-39], solidification of MSWIFA through co-mechanical treatment with CFBCFA also 
exhibits excellent mechanical performance, and seems to more suitable as a substitute for cement solidification technology.

Table 3. The porosity and compressive strength of solidified bodies.

\begin{tabular}{ccccc}
\hline Material & $\begin{array}{c}\text { Compressive Strength } \\
\text { (MPa) }\end{array}$ & $\begin{array}{c}\text { SD-c } \\
\text { (MPa) }\end{array}$ & $\begin{array}{c}\text { Porosity } \\
\text { (\%) }\end{array}$ & $\begin{array}{c}\text { SD-p } \\
\text { (\%) }\end{array}$ \\
\hline CFBCFA based solidified bodies & 36.70 & 1.09 & 18.00 & 0.45 \\
Cement based solidified bodies & 11.28 & 0.55 & 24.50 & 0.19 \\
\hline
\end{tabular}

${ }^{1}$ SD-c: standard deviation of compressive strength, ${ }^{2}$ SD-p: standard deviation of porosity.

\subsection{Leaching}

In Table 4, the leaching concentrations of heavy metals in MSWIFA are sharply declining and far below the permitted values of Chinese National Standards GB 5085.3-2007 after solidification treatment, indicating the remarkable leaching resistance of CFBCFA and cement based solidified bodies. Hence, solidification of MSWIFA through co-mechanical treatment with CFBCFA could be an ideal substitute for cement solidification technology. Actually, the solidification mechanisms of the heavy metals in CFBCFA based solidified bodies could be divided into three processes: physical encapsulation, chemical absorption, and precipitation. Firstly, C-S-H forms a barrier on the surface of MSWIFA particles during the hydration process, restricting the migration of heavy metal ions through mechanical processes or chemical reactions [40]. Secondly, ettringite and gismondine in solidified bodies may adsorb heavy metals through ions exchange [41,42]. Thirdly, a high alkalinity environment during the solidification process probably helps to lock heavy metals in the shape of precipitation [43].

Table 4. Leaching results for MSWIFA and solidified bodies (mg/L).

\begin{tabular}{ccccc}
\hline Elements & GB 5085.3-2007 & MSWIFA & $\begin{array}{c}\text { CFBCFA Based } \\
\text { Solidified Bodies }\end{array}$ & $\begin{array}{c}\text { Cement Based } \\
\text { Solidified Bodies }\end{array}$ \\
\hline $\mathrm{Zn}$ & 100.00 & 85.8300 & 0.5086 & 0.0358 \\
$\mathrm{~Pb}$ & 5.00 & 2.9457 & 0.0519 & 0.0939 \\
$\mathrm{Cu}$ & 100.00 & 18.0450 & 0.6462 & 0.1097 \\
$\mathrm{Cd}$ & 1.00 & 5.1914 & 0.1222 & 0.0998 \\
$\mathrm{Cr}$ & 5.00 & 16.0800 & 0.6145 & 0.8734 \\
\hline
\end{tabular}

\section{Conclusions}

This work investigates the solidification performance of MSWI fly ash through co-mechanical treatment with CFBC fly ash, compared to the cement solidification technology. The results prove that the solidification of MSWIFA through co-mechanical treatment could be an ideal substitute for cement solidification technology. The main conclusions could be drawn as follows:

1. The CFBCFA based solidified bodies exhibit better compressive strength than cement based solidified bodies. The compressive strength of CFBCFA based solidified bodies measures up to 36.7 $\mathrm{MPa}$ after $28 \mathrm{~d}$ curing, while cement based solidified bodies could only reach $11.28 \mathrm{MPa}$, which is correlated to the lower porosity and more compact internal structure of CFBCFA based solidified bodies;

2. XRD, FT-IR, and TG-DTA analyses indicate that the predominant hydrate products in CFBCFA and cement based solidified bodies are $\mathrm{C}-\mathrm{S}-\mathrm{H}, \mathrm{AFt}$, and FS. Moreover, large amounts of $\mathrm{Ca}(\mathrm{OH})_{2}$ originating from MSWIFA are conducive to promoting the hydration reaction extent and compressive strength of the CFBCFA based solidified bodies, while excessive $\mathrm{Ca}(\mathrm{OH})_{2}$ is harmful to the compressive strength development of the cement based solidified bodies;

3. CFBCFA based solidified bodies possess excellent leaching resistance. The heavy metals $(\mathrm{Zn}, \mathrm{Cu}$, $\mathrm{Cr}, \mathrm{Cd}$, and $\mathrm{Pb}$ ) concentrations in the extraction solution are far below the requirements of 
Chinese National Standard GB 5085.3-2007. The heavy metals in CFBCFA based solidified bodies are immobilized mainly depending on a combination of physical encapsulation and chemical absorption. In addition, partial heavy metal ions are locked in the form of precipitation due to the high alkalinity of the reaction system.

Author Contributions: Conceptualization, Z.Y. and Z.X.; methodology, Z.Y. and Z.X.; validation, Z.X.; investigation, Z.Y., Q.S. and X.C.; resources, Z.X.; data curation, Z.Y., Y.L., R.A., X.J. and H.L.; writing-original draft preparation, Z.Y., Q.S. and X.C.; writing-review and editing, Z.Y., Q.S., X.C., Z.X., Z.J. and X.P., Y.L., R.A., X.J. and H.L. All authors have read and agreed to the published version of the manuscript.

Funding: This research was funded by the National Natural Science Foundation of China, grant number 51404200; the Science and Technology Innovation Talent Foundation of Sichuan Province, grant number 20132065; and the Southwest University of Science and Technology, grant numbers 14tdgk04, 17lzx618, and 18lzx654. The APC was funded by the State Key Laboratory of Solid Waste Reuse for Building Materials, grant number SWR-2013-005.

Acknowledgments: The authors acknowledge the Key Laboratory of Solid Waste Treatment and Resource Recycle, Ministry of Education and the Analysis and Test Center (Southwest University of Science and Technology) for their support in the experiment and analysis conditions.

Conflicts of Interest: The authors declare no conflict of interest.

\section{References}

1. Bie, R.; Pei, C.; Song, X.; Ji, X. Characteristics of municipal solid waste incineration fly ash with cement solidification treatment. J. Energy Inst. 2016, 89, 704-712. [CrossRef]

2. Quina, M.J.; Bontempi, E.; Bogush, A.; Schlumberger, S.; Weibel, G.; Braga, R.; Funari, V.; Hyks, J.; Rasmussen, E.; Lederer, J. Technologies for the management of MSW incineration ashes from gas cleaning: New perspectives on recovery of secondary raw materials and circular economy. Sci. Total Environ. 2018, 635, 526-542. [CrossRef] [PubMed]

3. Benassi, L.; Dalipi, R.; Consigli, V.; Pasquali, M.; Borgese, L.; Depero, L.E.; Clegg, F.; Bingham, P.A.; Bontempi, E. Integrated management of ash from industrial and domestic combustion: A new sustainable approach for reducing greenhouse gas emissions from energy conversion. Environ. Sci. Pollut. Res. 2017, 24, 14834-14846. [CrossRef] [PubMed]

4. Malviya, R.; Chaudhary, R. Factors affecting hazardous waste solidification/stabilization: A review. J. Hazard. Mater. 2006, 137, 267-276. [CrossRef] [PubMed]

5. Qian, G.; Cao, Y.; Chui, P.; Tay, J. Utilization of MSWI fly ash for stabilization/solidification of industrial waste sludge. J. Hazard. Mater. 2006, 129, 274-281. [CrossRef] [PubMed]

6. Guo, X.; Shi, H.; Chen, L.; Dick, W.A. Alkali-activated complex binders from class C fly ash and Ca-containing admixtures. J. Hazard. Mater. 2010, 173, 480-486. [CrossRef] [PubMed]

7. Utilization of Municipal Solid Waste Incinerator Fly Ash in Cement Mortars. Available online: https:// digitalcommons.njit.edu/cgi/viewcontent.cgi?article=1472\&context=dissertations (accessed on 15 November 2019).

8. Sheng, G.; Li, Q.; Zhai, J. Investigation on the hydration of CFBC fly ash. Fuel 2012, 98, 61-66. [CrossRef]

9. Wenshi, L.; Haobo, H.; Chuhao, Z.; Dajie, Z. Feasibility study on solidification of municipal solid waste incinerator fly ash with circulating fluidized bed combustion coal fly ash. Waste Manag. Res. 2009, 27, 258-266. [CrossRef]

10. Pourghahramani, P.; Forssberg, E. Microstructure characterization of mechanically activated hematite using XRD line broadening. Int. J. Miner. Process. 2006, 79, 106-119. [CrossRef]

11. Wu, C.W.; Sun, C.J.; Gau, S.H.; Hong, C.L.; Chen, C.G. Mechanochemically induced synthesis of anorthite in MSWI fly ash with kaolin. J. Hazard. Mater. 2013, 244, 412-420. [CrossRef]

12. Sekulic, Z.; Petrov, M.; Zivanovic, D. Mechanical activation of various cements. Int. J. Miner. Process. 2004, 74, S355-S363. [CrossRef]

13. Sekulić, Ž.; Popov, S.; Đuričić, M.; Rosić, A. Mechanical activation of cement with addition of fly ash. Mater. Lett. 1999, 39, 115-121. [CrossRef]

14. Brandstetr, J. Properties and use of solid residue from fluidized bed coal combustion. Fuel Energy Abstr. 1996, 38, 320. [CrossRef] 
15. Fu, X.; Qin, L.; Zhai, J.; Sheng, G.; Li, F. The physical-chemical characterization of mechanically-treated CFBC fly ash. Cem. Concr. Compos. 2008, 30, 220-226. [CrossRef]

16. Zhong, S.; Ni, K.; Li, J. Properties of mortars made by uncalcined FGD gypsum-fly ash-ground granulated blast furnace slag composite binder. Waste Manag. 2012, 32, 1468-1472. [CrossRef]

17. Hashemi, S.S.G.; Mahmud, H.B.; Ghuan, T.C.; Chin, A.B.; Kuenzel, C.; Ranjbar, N. Safe disposal of coal bottom ash by solidification and stabilization techniques. Constr. Build. Mater. 2019, 197, 705-715. [CrossRef]

18. Liao, W.P.; Yang, R.; Kuo, W.T.; Huang, J.Y. The application of electrocoagulation for the conversion of MSWI fly ash into nonhazardous materials. J. Environ. Manag. 2014, 137, 157-162. [CrossRef]

19. Frias, M.; Goñi, S.; García, R.; Vigil de La Villa, R. Seawater effect on durability of ternary cements. Synergy of chloride and sulphate ions. Compos. Part B Eng. 2013, 46, 173-178. [CrossRef]

20. Li, X.G.; Chen, Q.B.; Ma, B.G.; Huang, J.; Jian, S.W.; Wu, B. Utilization of modified CFBC desulfurization ash as an admixture in blended cements: Physico-mechanical and hydration characteristics. Fuel 2012, 102, 674-680. [CrossRef]

21. Li, F.; Qin, L.; Jianping Zhai, A.; Sheng, G. Effect of Zeolitization of CFBC Fly Ash on Immobilization of $\mathrm{Cu}^{2+}$, $\mathrm{Pb}^{2+}$, and $\mathrm{Cr}^{3+}$. Ind. Eng. Chem. Res. 2007, 46, 7087-7095. [CrossRef]

22. Huang, X.; Huang, T.; Li, S.; Muhammad, F.; Xu, G.; Zhao, Z.; Yu, L.; Yan, Y.; Li, D.; Jiao, B. Immobilization of chromite ore processing residue with alkali-activated blast furnace slag-based geopolymer. Ceram. Int. 2016, 42, 9538-9549. [CrossRef]

23. Zhen, G.; Lu, X.; Zhao, Y.; Niu, J.; Chai, X.; Su, L.; Li, Y.Y.; Liu, Y.; Du, J.; Hojo, T.; et al. Characterization of controlled low-strength material obtained from dewatered sludge and refuse incineration bottom ash: Mechanical and microstructural perspectives. J. Environ. Manag. 2013, 129, 183-189. [CrossRef] [PubMed]

24. Eskander, S.B.; Saleh, H.M. Cement mortar-degraded spinney waste composite as a matrix for immobilizing some low and intermediate level radioactive wastes: Consistency under frost attack. J. Nucl. Mater. 2012, 420, 491-496. [CrossRef]

25. Dung, N.T. Hydration Process and Compressive Strength of Slag-CFBC Fly Ash Materials without Portland Cement. J.Mater. Civ. Eng. 2014, 27. [CrossRef]

26. Fermo, P.; Cariati, F.; Pozzi, A.; Tettamanti, M.; Collina, E.; Pitea, D. Analytical characterization of municipal solid waste incinerator fly ash. Fresenius' J. Anal. Chem. 2000, 366, 267-272. [CrossRef]

27. Mollah MY, A.; Lu, F.; Cocke, D.L. An X-ray diffraction (XRD) and Fourier transform infrared spectroscopic (FT-IR) characterization of the speciation of arsenic (V) in Portland cement type-V. Sci. Total Environ. 1998, 224, 57-68. [CrossRef]

28. Vedalakshmi, R.; Sundara Raj, A.; Srinivasan, S.; Ganesh Babu, K. Quantification of hydrated cement products of blended cements in low and medium strength concrete using TG and DTA technique. Thermochim. Acta 2003, 407, 49-60. [CrossRef]

29. Shi, Z.; Geiker, M.R.; Lothenbach, B.; De Weerdt, K.; Garzón, S.F.; Enemark-Rasmussen, K.; Skibsted, J. Friedel's salt profiles from thermogravimetric analysis and thermodynamic modelling of Portland cement-based mortars exposed to sodium chloride solution. Cem. Concr. Compos. 2017, 78, 73-83. [CrossRef]

30. UbbrìAco, P.; Calabrese, D. Solidification and stabilization of cement paste containing fly ash from municipal solid waste. Thermochim. Acta 1998, 321, 143-150. [CrossRef]

31. Nabajyoti, S.; Shigeru, K.; Toshinori, K. Production of cement clinkers from municipal solid waste incineration (MSWI) fly ash. Waste Manag. 2007, 27, 1178-1189. [CrossRef]

32. Lancellotti, I.; Ponzoni, C.; Bignozzi, M.C.; Barbieri, L.; Leonelli, C. Incinerator Bottom Ash and Ladle Slag for Geopolymers Preparation. Waste Biomass Valorization 2014, 5, 393-401. [CrossRef]

33. Moropoulou, A.; Bakolas, A.; Aggelakopoulou, E. Evaluation of pozzolanic activity of natural and artificial pozzolans by thermal analysis. Thermochim. Acta 2004, 420, 135-140. [CrossRef]

34. Veiga, K.K.; Gastaldini, A.L.G. Sulfate attack on a white Portland cement with activated slag. Constr. Build. Mater. 2012, 34, 494-503. [CrossRef]

35. Cook, R.A.; Hover, K.C. Mercury porosimetry of hardened cement pastes. Cem. Concr. Res. 1999, 29, 933-943. [CrossRef]

36. Hanisková, D.; Bartoníčková, E.; Koplík, J.; Opravil, T. The Ash from Fluidized Bed Combustion as a Donor of Sulfates to the Portland Clinker. Procedia Eng. 2016, 151, 394-401. [CrossRef] 
37. Luna Galiano, Y.; Fernández Pereira, C.; Vale, J. Stabilization/solidification of a municipal solid waste incineration residue using fly ash-based geopolymers. J. Hazard. Mater. 2011, 185, 373-381. [CrossRef] [PubMed]

38. Liu, X.; Zhao, X.; Yin, H.; Chen, J.; Zhang, N. Intermediate-calcium based cementitious materials prepared by MSWI fly ash and other solid wastes: Hydration characteristics and heavy metals solidification behavior. J. Hazard. Mater. 2018, 349, 262-271. [CrossRef]

39. Zhang, D.; Liu, W.; Hou, F.; He, X. Strength, leachability and microstructure characterisation of Na2SiO 3-activated ground granulated blast-furnace slag solidified MSWI fly ash. Waste Manag. Res. 2007, 25, 402-407. [CrossRef]

40. Sobiecka, E.; Obraniak, A.; Antizar-Ladislao, B. Influence of mixture ratio and $\mathrm{pH}$ to solidification/stabilization process of hospital solid waste incineration ash in Portland cement. Chemosphere 2014, 111, 18-23. [CrossRef]

41. Zhao, S.; Chen, Z.; Shen, J.; Kang, J.; Zhang, J.; Shen, Y. Leaching mechanisms of constituents from fly ash under the influence of humic acid. J. Hazard. Mater. 2017, 321, 647-660. [CrossRef]

42. Khale, D.; Chaudhary, R. Mechanism of geopolymerization and factors influencing its development: A review. J. Hazard. Mater. 2007, 42, 729-746. [CrossRef]

43. Komarneni, S.; Breval, E.; Roy, D.M.; Roy, R. Reactions of some calcium silicates with metal cations. Cem. Concr. Res. 1988, 18, 204-220. [CrossRef]

(C) 2019 by the authors. Licensee MDPI, Basel, Switzerland. This article is an open access article distributed under the terms and conditions of the Creative Commons Attribution (CC BY) license (http://creativecommons.org/licenses/by/4.0/). 